\title{
Repointing Mortars for Conservation of a Historic Stone Building in Trinity College, Dublin
}

\author{
Aidan Duffy \\ University of Dublin, Trinity College, aidan.duffy@tudublin.ie \\ Tim P. Cooper \\ University of Dublin Trinity College \\ Simon H. Perry \\ University of Dublin, Trinity College
}

Follow this and additional works at: https://arrow.tudublin.ie/engschcivart

Part of the Civil Engineering Commons

\section{Recommended Citation}

Duffy, A. P., Cooper, T. P. and Perry, S. H. (1993) Repointing mortars for the conservation of a historic building at Trinity College, Dublin, in Materials and Structures, RILEM, 26, pp 302-306 doi:10.1007/ BF02472952

This Article is brought to you for free and open access by the School of Civil and Structural Engineering at ARROW@TU Dublin. It has been accepted for inclusion in Articles by an authorized administrator of ARROW@TU Dublin. For more information, please contact arrow.admin@tudublin.ie, aisling.coyne@tudublin.ie, gerard.connolly@tudublin.ie.

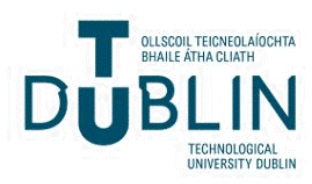




\title{
Repointing mortars for conservation of a historic stone building in Trinity College, Dublin
}

\author{
A. P. DUFFY, T. P. COOPER, * S. H. PERRY \\ Department of Civil, Structural and Environmental Engineering and ${ }^{*}$ Director of Buildings Office, Trinity College, Dublin 2, Ireland
}

With atmospheric pollution causing building stone to decay at accelerated rates, conservation of historic stone monuments is becoming an increasingly important issue. Mortar joints have a marked effect on how moisture moves in a wall and, hence, on how the wall weathers. Not only does mortar bind stones together, but also a good mortar will prevent the ingress of moisture (and pollutants), enable the buildings to dry out, accommodate movement and will not act as a source of harmful chemicals capable of attacking the surrounding stone. Thus, poor mortar can have deleterious effects on the stonework. This paper, which is the result of research sponsored by the Commission of European Communities, considers a number of commonly used, and some more rarely used, pointing mortars, and assesses them with a view to using the most successful for repointing a historic stone building in Trinity College, Dublin.

\section{INTRODUCTION}

Regent House is the facade most commonly associated with Trinity College, Dublin. It was built in 1756 of Dublin granite and Portland limestone, and faces on to one of the busiest streets of the city. Consequently, the facade has suffered much discoloration and damage caused by atmospheric pollution [1]. In 1989, Trinity College took the decision to carry out a conservation project, the main thrust of which was the cleaning of the badly blackened and decayed stonework. During this programme, it became evident that it was necessary to repoint the entire building. The decision to repoint was an easy one - not only had bond been lost between the mortar and stone, allowing ingress of moisture, but in the previous maintenance programme the mortar itself had been coloured black to match the then blackened stonework. The choice of which mortar to use for repointing, subsequent to raking the joints, was a more difficult decision to make since a wrong choice could significantly increase the rate of decay of stone. Findings of a previous research project had indicated that areas of high decay on the granite buildings in Trinity College also corresponded to regions of high calcium content in the wall [2]. Since almost all mortars contain some form of soluble calcium, it was decided to carry out some experimental research into the chemical and mechanical properties of a number of different repointing mortars to determine which mortar would cause least damage to the stone while fulfilling all necessary functions.

\section{PROBLEMS ASSOCIATED WITH REPOINTING MORTARS}

The choice of pointing mortar is an important factor in any conservation project, although it is often not given due consideration. Pointing mortars should prevent the ingress of moisture which, if allowed, can seriously affect the fabric of the building [3]. Some of the more important factors are considered below.

\subsection{Strength}

The strength of a mortar depends on, firstly, the amount of void space between the aggregate particles that has been filled with binder and, secondly, the type of binder used. Typically, sands have a void ratio of between 25 and $33 \%$, hence the reason for the common mix proportions of between $2: 1$ and $3: 1$ sand:binder [4] Strong mortars restrain movement of the building units rather than accommodate or absorb it. Such restraint can result in the cracking of the building units; either the edges crack and spall (often evident in stone [5]), or the entire unit may crack (more common for bricks [6]). Indeed, the mortar should preferably deform significantly before failure, thus minimizing this risk of brittle failure 
or cracking. Excessively strong mortars may also cause serious problems when it becomes necessary to rake and repoint at a later date, as some stone tends to break away and come off with a strong mortar as it is raked out. Hence, a repointing mortar should be weaker than the surfaces of the building materials in contact with it.

\subsection{Soluble salts}

The formation of salts within pores and microcracks in the stone is probably the main reason for decay [7]. Calcium, sodium and magnesium present in the building (in both the stone and the mortar) dissolve and then react with sulphates present in the air and rain-water to form calcium sulphate (especially gypsum, a form of hydrated calcium sulphate which is the most common and most damaging), sodium sulphate and magnesium sulphate. These may exist in different hydrated forms depending on the moisture content in the wall at any particular time. It is this property of being able to exist in different hydrated forms [8], plus the fact that the crystals will grow [9], that make these salts so damaging. As they change their hydrated form, they either expand or contract, exerting forces on the stone matrix. These forces lead to the formation of cracks within the stone which, in turn, allow the further ingress of soluble salt-rich water, causing further growth of the salt crystals and, hence, further damage to the stone. Eventually, the entire surface of the stone is disrupted, and starts to disintegrate. For this reason, a pointing mortar should be low in soluble salts, especially those of calcium.

\subsection{Other factors}

The voids in impermeable mortars are usually filled with a binder, which inhibits the evaporation of moisture through the mortar. Instead, water moves through the building unit, saturating it [10]. If this occurs in cold conditions, freeze-thaw damage may result, or alternatively soluble salts may be leached to the surface of the unit [11].

Strong mortars are the main cause of shrinkage problems, but very wet mixes also lead to excessive shrinkage, especially when used in thick joints. Shrinkage leads to loss of bond, resulting in the penetration of rain-water and subsequent damage of the wall. In an extreme case, the entire re-pointed joint may fall out.

Good workability is an important factor in the design of a mix, making the bricklayer's job easier and quicker, and leading to a better finish. It is governed largely by cement content and water/cement ratio. Lime is the most commonly used additive for increasing workability, but plasticizers can also be used effectively.

Colour, texture and finish all have a bearing on the appearance of the mortar. The colour of the mortar is strongly influenced by the colour of the binder, as well as that of the sand. Texture is mainly influenced by the type of sand used.

\section{EXPERIMENTAL PROGRAMME}

\subsection{Mixes chosen}

The mortars selected for the tests represented a cross-section of those most commonly used in the building and conservation industries, together with some new formulations considered promising. A variety of cement mortars, both with and without plasticizer, was selected together with a cement/lime mortar, chosen to represent the common building mortars. Lump lime, which had been slaked a number of months previously, was combined with cement and sand to produce a mix close to that recommended by conservationists. PFA, a pozzolanic material, was chosen as a cement replacement in one mix as it was thought that it would have a reduced soluble salt content. In another mix, $\mathrm{Ba}(\mathrm{OH})_{2}$ was substituted for $\mathrm{Ca}(\mathrm{OH})_{2}$ (lime), the logic here being that the barium would either react with the cement to form complex crystals on setting, or else would set by carbonation in the same way as lime. If the barium was then washed out into solution by rain-water, it would form barium sulphate $\left(\mathrm{BaSO}_{4}\right)$, which is far less soluble than gypsum $\left(\mathrm{CaSO}_{4} \cdot 2 \mathrm{H}_{2} \mathrm{O}\right)$. Since barium sulphate has only one hydrated state [12], it would not exert forces on the stone matrix by expanding and contracting as the moisture content varied. Also, as $\mathrm{BaSO}_{4}$ is almost insoluble in water, it would act as a protective barrier, preventing the dissolution of the stone. Details of the different mortars are given in Table 1.

Table 1 Mix constituents and proportions for the different mortars

\begin{tabular}{lll}
\hline Mix code & Mix materials & $\begin{array}{l}\text { Mix proportion } \\
\text { (by weight) }\end{array}$ \\
\hline A & Sand/cement & $3: 1$ \\
B & Sand/cement/lime & $6: 1: 1$ \\
C & Sand/cement/lime putty & $6: 1: 1$ \\
D & Sand/cement/PFA & $6: 1: 1$ \\
E & Sand/cement/Ba(OH) 2 & $6: 1: 1$ \\
F & Sand/cement with plasticizer & $6: 1$ \\
G & Sand/cement with plasticizer & $10: 1$ \\
\hline
\end{tabular}

\subsection{Tests}

Because of time constraints imposed by the restoration programme, it was decided to carry out tests to determine only the most important characteristics of the mortars.

Ultimate strength tests were conducted on cubes (75 mm) using a Denison compression machine at low rates of loading $\left(5 \mathrm{kN} \mathrm{min}^{-1}\right)$. Vertical strain was monitored using electrical resistance strain gauges $(10 \mathrm{~mm}$ in length). Flexural strength tests were undertaken on $40 \mathrm{~mm} \times 40 \mathrm{~mm} \times 160 \mathrm{~mm}$ prisms, with supports at $100 \mathrm{~mm}$ separation, and loaded at mid-span. Load was applied at a constant rate of strain $\left(0.25 \mathrm{~mm} \mathrm{~s}^{-1}\right)$ until failure. 
Chemical tests involved eluting the mortar samples, filtering them and monitoring the levels of soluble salts in the mortars using chemically suppressed ion chromatography. Total soluble calcium $\left(\mathrm{Ca}^{2+}\right)$, sodium $\left(\mathrm{Na}^{2+}\right)$, magnesium $\left(\mathrm{Mg}^{2+}\right)$, potassium $\left(\mathrm{K}^{+}\right)$, chloride $\left(\mathrm{Cl}^{2-}\right)$, nitrate $\left(\mathrm{NO}_{3}^{2-}\right)$, sulphate $\left(\mathrm{SO}_{4}^{2-}\right)$ and carbonate $\left(\mathrm{CO}_{3}^{2-}\right)$ were taken as indicators of the damaging chemical effects of the mortar. Conductivity of the eluted sample was monitored, and taken as a measure of total soluble salt content.

\section{RESULTS AND DISCUSSION}

The mortars were tested at 7 and 28 days using the different mechanical and chemical tests outlined above; raking and repointing tests were carried out with the most promising mix.

\subsection{Mechanical results}

It can be seen in Fig. 1 that the ultimate strength of the mix A was nearly twice that of the next strongest mortar, mix D. Little difference was found between mix B and mix $\mathrm{C}$, and mix $\mathrm{F}$ was of comparable strength to these, perhaps indicating that the lime does not contribute significantly to the strength of the mortar (at least, after only 28 days). Mix $\mathrm{E}$ was unusual in that although it had the same cement content as the lime mixes, it had the same low strength range as mix $G$ (which had a much lower cement content).

The secant modulus $\left(E_{\mathrm{sec}}\right)$ for mix A was the highest. Thus, of all the mortars, mix A would deform least under a given load and might, therefore, damage the stone to a greater extent than the other mortars (which have lower moduli) if there is movement of the wall. The lime mortars, and mixes $D$ and $F$, were all found to have similar values of $E_{\mathrm{sec}}$, while mixes $\mathrm{E}$ and $\mathrm{G}$ had the lowest values.

Mix A was found to have the highest flexural strength, with mix D next highest. The lime mortars and mix $\mathrm{F}$ were found to have approximately the same mid-range strengths; lowest were mixes $\mathrm{E}$ and $\mathrm{G}$.

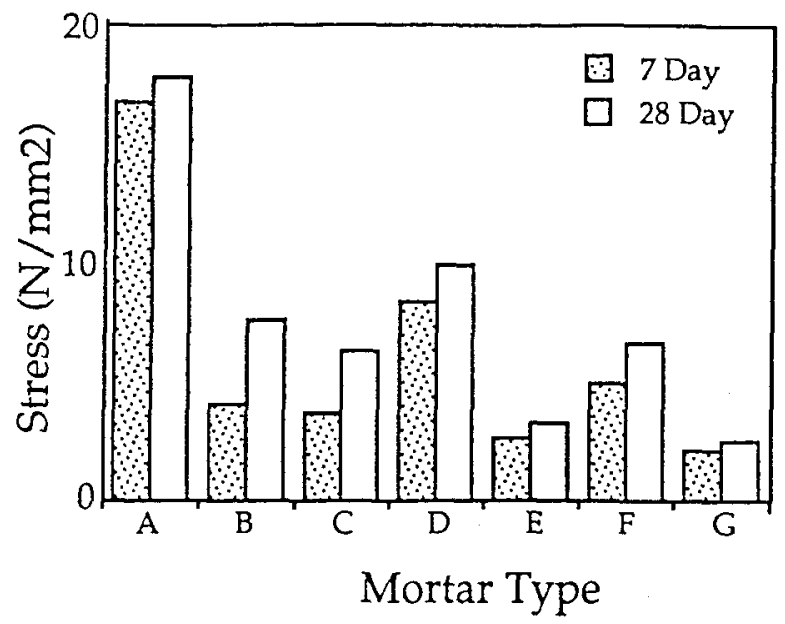

Fig. 1 Ultimate crushing stresses for different mortars.

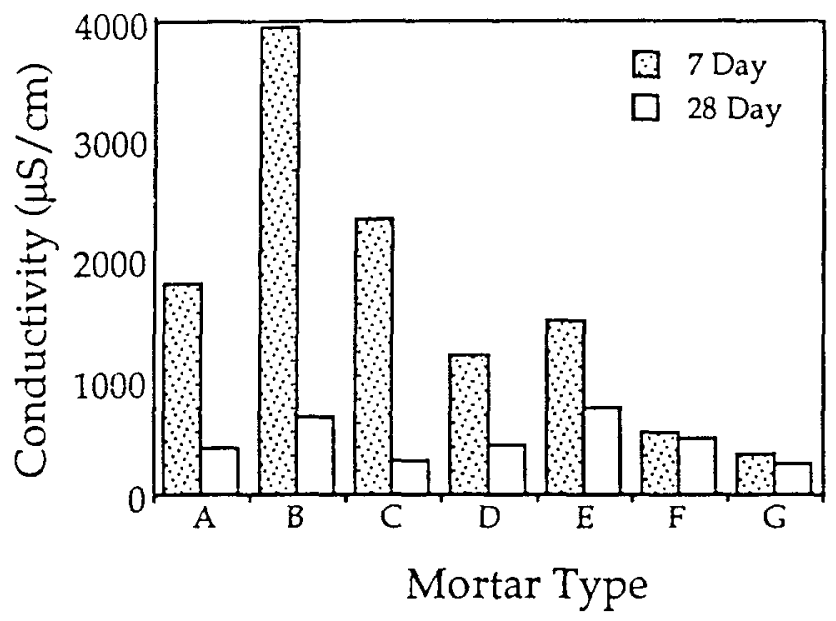

Fig. 2 Conductivity of eluted mortar samples.

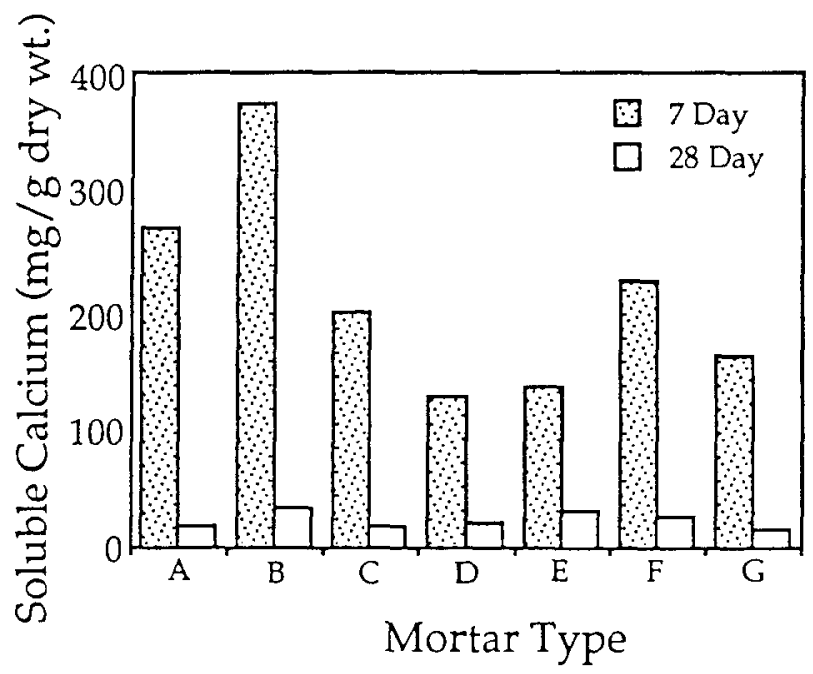

Fig. 3 Soluble calcium content of mortar samples.

\subsection{Chemical results}

Results for conductivity, a measure of the total soluble salt content, are shown in Fig. 2. It can be seen that conductivity drops very significantly between 7 and 28 days for all mortar samples, excepting the $F$ and $G$ mixes. The results at 28 days show that mixes $\mathrm{B}$ and $\mathrm{E}$ have the highest soluble salt contents, mixes $\mathrm{C}$ and $\mathrm{G}$ the lowest, and mixes A, D and $\mathrm{F}$ lie about mid-range.

The soluble calcium content (Fig. 3) reflects a similar trend to that shown by conductivity. There is a large fall in soluble calcium content between 7 and 28 days. The highest values were for mixes $\mathrm{B}$ and $\mathrm{E}$. Mixes A, C and $\mathrm{G}$ gave the lowest values.

After 28 days, soluble magnesium and sodium contents were found to be very low, with concentrations lying below 1 and $0.5 \mathrm{mg} \mathrm{g}^{-1}$ (dry weight), respectively. Soluble carbonate content is an indication of the total amount of soluble calcium present in the mortar. For mixes $\mathrm{B}$ and $\mathrm{C}$, the carbonate content decreased significantly between 7 and 28 days. This may have been due to $\mathrm{CaCO}_{3}$ combining with the cement crystals during setting. There was no significant change between the 7 and 28 day results for mixes $\mathrm{A}$ and $\mathrm{D}$. The soluble 
carbonate content of mix $\mathrm{E}$ increased significantly, perhaps due to slow carbonation of the $\mathrm{Ba}(\mathrm{OH})_{2}$ to $\mathrm{BaCO}_{3}$.

The concentrations of soluble sulphate dropped dramatically between 7 and 28 days, and all samples at 28 days were found to have a soluble sulphate content of 3 to $4 \mathrm{mg} \mathrm{g}^{-1}$ (dry weight) except mix E, which had a very low concentration of $0.4 \mathrm{mg} \mathrm{g}^{-1}$ (dry weight), and mixes $D$ and $F$, which were slightly higher than the norm.

Soluble nitrate, which forms nitric acid, and which also encourages the oxidation of $\mathrm{SO}_{2}$ to sulphuric acid, was found to be negligible in all samples after 28 days.

\section{CONCLUSIONS}

From these findings, a modified version of mix $G$ was considered to be most suitable for the repointing of Regent House. This was a 9:1 sand:cement mix with plasticizer mortar. This mix (properties given in Table 2) was chosen for the following reasons:

Table 2 Chemical and mechanical results for the mortar used in Regent House

\begin{tabular}{ll}
\hline Test & Result \\
\hline Ultimate crushing stress $\left(\mathrm{N} \mathrm{mm}^{-2}\right)$ & 2.7 \\
Conductivity $\left(\mathrm{S} \mathrm{cm}^{-1}\right)$ & $213 \times 10^{-6}$ \\
Soluble ion contents $\left(\mathrm{mg} \mathrm{g}^{-1}\right.$ dry weight $)$ & \\
$\quad$ Calcium & 19.9 \\
Magnesium & 0.1 \\
Potassium & 0.4 \\
Sodium & 0.3 \\
Carbonate & 60.2 \\
Sulphate & 6.0 \\
Nitrate & 9.2 \\
\hline
\end{tabular}

(i) It was found to be a sufficiently weak mortar. Ultimate crushing strength stress, the secant modulus and flexural strength, at 28 days, were all low at 2.7, 4210 and $2.3 \mathrm{~N} \mathrm{~mm}^{-2}$, respectively. Also, because the mortar has a low binder content, it could be assumed that it was sufficiently permeable, as there would be enough void space free to allow movement of moisture.

(ii) It was the leanest mix which could be satisfactorily worked by the bricklayer.

(iii) Soluble salt content at 28 days was low, with a total conductivity value of $213 \times 10^{-6} \mathrm{~S} \mathrm{~cm}^{-1}$. Hence, the possibility of the mortar acting as a source of harmful soluble salts was reduced.

(iv) For aesthetic reasons, the colour chosen was a light one; the repointing, similar in colour to the cleaned granite, was not obtrusive nor did it overemphasize the ashlar stones. The light colour was obtained by using a high sand content in the mix $(9: 1$ sand:cement by weight), and by using a light-coloured sand. A light-coloured binder, composed of a mixture of $25 \%$ grey and $75 \%$ white cement, was used. A flush finish was given to the mortar, and a 'sack-rubbed' texture was obtained by brushing with a stiff bristle brush.

\section{ACKNOWLEDGEMENTS}

This work formed part of an EC research programme entitled 'Effects of Air Pollution on Historic Buildings and Monuments: European Collaborative Programme of Research' which was made possible by funding provided by the Commission of the European Communities (Contract EV4V-0048-IRL). The authors wish to thank Emer Bell for carrying out the chemical analysis, to Trinity College Buildings Office who provided much practical advice and to Mary Kenny for typing the manuscript.

\section{REFERENCES}

1. Johnson, J., Haneef, S., Hepburn, B., Hutchinson, A., Thompson, G. and Wood, G., 'Laboratory exposure systems to simulate atmospheric degradation of building stone under dry and wet deposition conditions', Atmos. Envir. 24A (10) (1990) 2585-2592.

2. Cooper, T., Dowding, P., Lewis, J. O., Mulvin, L., O'Brien, P., Olley, J. and O'Daly, G., 'Contribution of calcium from limestone and mortar to the decay of granite walling', in Proceedings of Conference on Science, Technology and European Cultural Heritage, Bologna, 1989, pp. 456-461.

3. Feilden, B., 'Conservation of Historic Buildings', 1st Edn (Butterworth, London, 1982).

4. BRE Digest 160:1973, 'Mortars for Bricklaying' (Buildings Research Establishment, London, 1973).

5. Beningfield, N., 'Aspects of cement-based mortars for brickwork and blockwork', Concrete 14 (1) (1980) 27-30.

6. Nash, W., 'Brickwork Repair and Restoration', 1st Edn (Attic Books, Sussex, 1986).

7. Amoroso, G. and Fassina, V., 'Stone Decay and Conservation', 1st Edn. (Elsevier, Amsterdam, 1983).

8. Livingston, R. and Baer, S., "Mechanisms of air pollution-induced damage to stone', in Proceedings of 6th World Congress on Air Quality, Paris, May 1983, Vol. 3, pp. 33-40.

9. Binda, L., Baronio, G and Charola, A., 'Deterioration of porous materials due to salt crystallization under different thermohygrometric conditions, 1: Brick', in Proceedings of 5th Congress on the Deterioration and Conservation of Stone, Lausanne, September 1985, Vol. 1 (Presses Polytechniques Romandes, Lausanne, 1985) pp. 279-288.

10. Schaffer, R., 'The Weathering of Natural Building Stones', 1st Edn (His Majesty's Stationery Office, London, 1932).

11. Harvey, J., 'Conservation of Buildings', 1st Edn (Baker, London, 1972).

12. 'Handbook of Chemistry and Physics', 63rd Edn (CRC Press, Florida, 1982). 


\section{RESUME}

Rejointoiement de mortiers pour la conservation d'un bâtiment historique en pierre, Trinity College, Dublin

Dans le cadre d'un programme de conservation et de maintenance, Trinity College, Dublin, a décidé de rejointoyer, après grattage de l'ancien mortier, l'ensemble d'un important bâtiment historique. Les options disponibles à l'époque étaient les suivantes: soit suivre les pratiques 'traditionnelles', telle l'utilisation de mortier à la chaux, soit utiliser les mortiers de ciment modernes. On disposait de peu de certitude scientifique pour guider le choix. Le collège prit donc la décision d'entreprendre des essais afin de pouvoir évaluer les choix possibles.

On résume ici les caractéristiques les plus importantes d'un mortier de rejointoiement, et les problèmes qu'elles sont susceptibles de causer dans les murs. On a évalué à l'aide d'essais mécaniques et chimiques un certain nombre de mortiers (mortiers ciment/chaux, ciment/plastifiant, ciment/hydroxyde de barium, ciment/cendres volantes). Au bout du compte, on a choisi d'utiliser un mortier de sable/ciment dans la proportion 9:1 pour le programme de restauration de Trinity College. On décrit les problèmes liés au grattage et au rejointoiement. 